\title{
Histopathological findings and helicobacterpylori infection frequency in 816 sleeve gastrectomy materials for morbid obesity
}

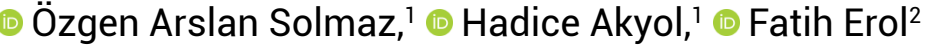 \\ 'Department of Pathology, Elazı̆̆ Training and Research Hospital, Elazığ, Turkey \\ 2Department of General Surgery, Malatya Private Gözde Academy Hospital, Malatya,Turkey
}

\begin{abstract}
Introduction: Morbid obesity is severe obesity that threatens and shortens a person's life. Today, surgery is almost the only treatment method that has been proven to treat morbid obesity. Endoscopic gastric examination is not performed preoperatively due to the complications that are associated with gastric pathologies that have not been defined. There are few studies for the purpose of determining histopathological findings in cases of sleeve gastrectomy specimens. It is thought that some postoperative complications may be related to existing histopathologic findings.
\end{abstract}

Materials and Methods: Preparations of 816 sleeve gastrectomy specimens examined in the pathology laboratory were reevaluated and evaluated histopathologically.

Results: Fifty-seven percent of 816 patients $(n=465)$ showed no significant anomaly. Fourteen percent $(n=114)$ showed non-Helicobacter-related gastritis. In $26 \%(n=212)$ of cases, Helicobacter pylori-associated gastritis was detected, and in $0.36 \%(n=3)$ of cases,specific gastritis (lymphocytic gastritis) was found. In $2.64 \%$ (22) of cases, intestinal metaplasia was observed. H.pylori was negative in $72 \%(n=588)$ and positive in $28 \%(n=228)$ of cases.

Conclusion: We concluded that H.pylori infections do not have a risk of postoperative complications. However, if premalignant lesions, such as intestinal metaplasia, are suspected, we believe that preoperative endoscopic examination of the stomach should be performed.

Keywords: Helicobacter pylori; histopathology; sleeve gastrectomy.

\section{Introduction}

Obesity is a major public health problem. The World Health Organization (WHO) defines obesity according to the body mass index (BMI), which is calculated by dividing an individual's body weight in kilograms by the square of the individual's height in meters $\left(\mathrm{kg} / \mathrm{m}^{2}\right)$. Ac- cording to this calculation, $30<\mathrm{BMI}<34.9 \mathrm{~kg} / \mathrm{m}^{2}$ are Class 1 obese, $35<\mathrm{BMI}<39.9 \mathrm{~kg} / \mathrm{m}^{2}$ are Class 2 obese, and $\mathrm{BMI}>40$ $\mathrm{kg} / \mathrm{m}^{2}$ are morbid obese (Class 3$){ }^{[1]}$ In recent years, WHO global estimates have been reported. Overall, about $13 \%$ of the adult population worldwide (11\% of men and $15 \%$ of women) was obese in 2014. The worldwide prevalence 
of obesity was more than doubled between 1980 and 2014 . ${ }^{[2]}$ According to the 2014 Health Survey conducted by the Turkish Statistical Institute, obese individuals constitute $19.9 \%$ of the population. ${ }^{[3]}$

Many factors play into obesity development and must be treated in endocrinologically, metabolically, and psychologically. ${ }^{[4]}$ Morbid obesity, on the other hand, is severe obesity that threatens and shortens a person's life. The most important factor responsible for the development of morbid obesity is the imbalance of energy in favor of food intake and storage ${ }^{[5]}$ Today, surgery is almost the only effective treatment method for the treatment of morbid obesity. ${ }^{[6]}$ Surgery known as sleeve gastrectomy, or tube stomach, is a relatively new approach among obesity surgeries. In fact, Marceau et al. ${ }^{[7]}$ defined this procedure in 1993as a restrictive component of biliopancreatic diversion, along with the duodenal switch procedure. In England, it has emerged as a variation of the Magenstrasse and Mill procedures. Laparoscopic sleeve gastrectomy (LSG) is the removal of two-thirds of the stomach's lateral left with astapler to reduce its size and shape it like a banana. In this operation, approximately $60 \%$ of the stomach is removed. Sleeve gastrectomy surgery is a method of treating severe obesity alone, accounting for $2 \%$ of all obesity surgeries. Since 2003-2004, there has been an increase in its single implementation. ${ }^{[8]}$

One of the main contraindications in sleeve gastrectomies is the presence of esophageal pathologies, such as reflux esophagitis and Barrett's esophagus. ${ }^{[9,10]}$ However, endoscopic gastric examination is not performed preoperatively due to the complications that are associated with gastric pathologies that have not been defined.

There are few studies for the purpose of determining histopathological findings in the cases of sleeve gastrectomy specimens, and the majority consist of a low number of patient groups. Our hospital has a comprehensive obesity surgery clinic serving many regions of Turkey, and our patient admission potential is very high. Therefore, we conclude that the results of this study are crucial in determining the histopathologic changes in patients with morbid obesity, and that it will be determinative in terms of preoperative examinations and treatments.

\section{Materials and Methods}

This is a retrospective study that involves reviewing the preparations examined in the pathology laboratory and evaluating the data on laparoscopic sleeve gastrectomy specimens for morbid obesity treatment between January 2014 and July 2016. After receiving approval from the Elazığ local ethics committee, H\&E- and Giemsa-stained preparations of 816 sleeve gastrectomy specimens examined in the pathology laboratory were reevaluated. In the evaluation of $\mathrm{H} \& \mathrm{E}$ preparations, the criteria were:

1. No significant abnormality: Cases without significant inflammation, with isolated, basally located lymphoid follicles or with mild non-specific parietal cell hyperplasia.

2. Non-Helicobacter-associated gastritis: Minimum criteria for this diagnostic category were the presence of chronic inflammation in the lamina propria. These cases may or may not have been associated with active inflammation. All cases of gastritis were stained with Giemsa to exclude the presence of Helicobacter.

4. Helicobacter-associated gastritis: Cases with Helicobacter-like organisms identified on H\&E or with the aid of a Giemsa.

5. Gastritis of a specific type: These cases included those with morphological features allowing classification as a gastritis of a specific type (e.g., lymphocytic or autoimmune atrophic gastritis). Cases of lymphocytic gastritis where Helicobacter organisms were identified were classified as Helicobacter-associated gastritis.

6. Polyps: The presence or absence of polyps was noted, and these were then classified according to subtype.

7. Intestinal metaplasia: Intestinal metaplasia of the stomach is a relative common finding that is associated with a modest increased risk of gastric carcinoma. It affects antral and body/fundic mucosa, with partial replacement by metaplastic goblet cells of intestinal morphology, absorptive cells and Paneth cells.

8. Other: Cases showing any other abnormal microscopic features ${ }^{[1]}$ were applied. In the preparations stained with Giemsa and under 400×light microscope magnification, Giemsa stained, curved, bar-shaped basils were sought in superficial mucus for the detection of Helicobacter pylori.

The data on complications in these patients in the postoperative period were examined from our hospital database.

\section{Statistical Evaluation}

Statistical analysis was performed using SPSS version 20 software (SPSS Inc., Chicago, IL, USA). A normalization 
assumption was used. Since the mode, median, and mean values calculated for all of the parameters were close to each other, all of the data were accepted as normally distributed. A point-double series correlation analysis was used to determine the direction of the correlation.

\section{Results}

Eighty-one percent ( $\mathrm{n}=661)$ of the specimens included in the study belonged to female patients and $19 \%(n=155)$ to male patients. The mean age of the patients was $35.7 \pm 9.7$ and ranged from 17 to 65 years. Fifty-seven percent of 816 patients $(n=465)$ showed no significant anomalies. Fourteen percent $(\mathrm{n}=114)$ showed non-Helicobacter-related gastritis. In 26\% ( $n=212$ ) of cases, H.pylori-associated gastritis was detected, and in $0.36 \%(\mathrm{n}=3)$, specific gastritis (lymphocytic gastritis) was found. In $2.64 \%(\mathrm{n}=22)$, intestinal metaplasia was observed. No other findings, such as malignancy, dysplasia, or polyps, were observed.

H. pylori was negative in $72 \%(\mathrm{n}=588)$ and positive in $28 \%$ $(n=228)$ of cases. H.pylori-associated gastritis was found in 212 of the positive cases, and normal histological findings were observed in 16 cases.

In the correlation analysis, no significant correlation was found in the Helicobacter presence and intestinal metaplasia with age and gender ( $p>0.05)$. Anastomosis leakage

Table 1. General and histopathologic features of the study group

\begin{tabular}{lcc} 
& $\mathbf{n}$ & $\%$ \\
\hline The mean age (Mean \pm SD) & $35.7 \pm 9.7$ \\
Gender & & \\
$\quad$ Female & 661 & 81 \\
$\quad$ Male & 155 & 19 \\
Histopathology & & \\
$\quad$ Non-significant abnormality & 465 & 57 \\
$\quad$ NHAG & 114 & 14 \\
Helicobacter associated gastritis & 212 & 26 \\
$\quad$ Gastritis of specific type & 3 & 0.36 \\
$\quad$ Polyps & - & - \\
Intestinal metaplasia & 22 & 2.64 \\
$\quad$ Other & - & - \\
Helicobacter Pylori & & \\
$\quad$ Positive & 228 & 28 \\
$\quad$ Negative & 588 & 72 \\
\hline
\end{tabular}

NHAG: Non-helicobacter associated gastritis; SD: Standard deviation. was observed in only eight cases postoperatively, but only one had H.pylori-associated gastritis. Statistically, there was no significant correlation found between the presence of H.pylori and developed complications ( $p>0.05$ ).

\section{Discussion}

Obesity is a globally serious health problem. Some 1.9 billion people are overweight, and 600 million are obese. In Central Asia, $74-86 \%$ of women and $69-77 \%$ of men are either obese (BMI $\geq 30$ ) or overweight (BMI $\geq 25-29.9$ ). ${ }^{[12]}$ Obesity is an important risk factor for gastrointestinal system pathologies, as well as cardiac issues, metabolic diseases, cancer, and respiratory-rheumatologic-dermatologic pathologies. It has been reported that gastro-esophageal reflux disease, erosive esophagitis, hiatal hernia, esophageal adenocarcinoma, and H. pylori infection are two to three times more common in obese patients than in normal ones. ${ }^{[13]}$ Despite the fact that H.pylori has a role in obesity development and increases the postoperative complications of obesity surgeries, it is not accepted as a negative factor for obesity surgeries. ${ }^{[14]}$

There are few studies on histopathologic changes in LSG materials. In Almazeedi et al.'s ${ }^{[15]}$ study, the histopathology results were identified in $488(74.4 \%)$ cases with chronic gastritis, 63 (9.6\%) with follicular gastritis, and $12(1.8 \%)$ with atrophic gastritis, and a total of $12(1.8 \%)$ cases showed findings other than gastritis, including $4(0.6 \%)$ cases of gastric polyps, $3(0.5 \%)$ cases of granulomatous disease, and $1(0.2 \%)$ case each of gastro-intestinal stromal tumor, gastro-intestinal autonomic nerve tumor, intestinal metaplasia, collagenous gastritis, and crypt cell apoptosis. H.pylori was discovered in 48 (7.3\%) of the patients.

In a study of 310 patients by Ohanessian et al., ${ }^{[16]}$ the histopathologic findings included the following: no pathological alteration in 214 patients $(69.0 \%)$, chronic inactive gastritis in 41 (13.2\%), fundic gland polyps in 17 (5.5\%), proton pump inhibitor therapy effect in $12(3.9 \%)$, H. pylori-associated chronic active gastritis in $10(3.2 \%)$, chronic active gastritis (H. pylori-negative) in 5 (1.6\%), chronic gastritis with intestinal metaplasia in $4(1.0 \%)$, gastrointestinal stromal tumor (GIST) in $3(1.0 \%)$, and hyperplastic polyp, granulomatous inflammation, xanthogranulomatous inflammation, and mucosal ulceration in 1 patient each $(0.3 \%)$.

Miller and colleagues conducted a study on 1,463 cases that showed no pathological changes $(80.2 \%)$. The most 
common changes seen were non-specific, non-Helicobacter-associated chronic gastritis (7.2\%), Helicobacter-associated gastritis $(6.8 \%)$, and benign fundic gland polyps (4.0\%). Other, rarer changes were lymphocytic gastritis, autoimmune atrophic gastritis, chronic gastritis with intestinal metaplasia, hyperplastic polyps, pancreatic heterotopia, GISTs, and a leiomyoma.

It is still controversial whether routine preoperative upper gastro-intestinal endoscopy should be performed in patients undergoing LSG. However, it should be done absolutely performed in symptomatic patients. Loewen et al. ${ }^{[17]}$ reported that endoscopy required medical treatment in $18 \%$ of the patients prior to surgery; however, the surgical planning changed in $1 \%$ of the patients. Preoperative routine upper gastrointestinal endoscopy enables the diagnosis of rarely observed gastric pathologies. Preoperative treatment of these patients is an important factor, which affects the success of bariatric surgery.

In this study, $57 \%$ of 816 patients $(n=465)$ showed no significant anomalies. Fourteen percent $(n=114)$ showed non-Helicobacter-related gastritis. In $26 \% \quad(n=212)$ of cases, H.pylori-associated gastritis was detected, and in $0.36 \%(n=3)$, specific gastritis (lymphocytic gastritis) was detected. In $2.64 \%(\mathrm{n}=22)$, intestinal metaplasia was observed. H.pylori was negative in $72 \%(\mathrm{n}=588)$ and positive in $28 \%$ ( $n=228)$. Compared with literature outside Turkey, normal gastric mucosa was found to be less common, but H.pylori-associated gastritis and H.pylori were detected more frequently than reported in the literature. However, in a study conducted by Arslan and colleagues in obese patients in Turkey, the prevalence of H.pylori was found to be $57.2 \%$ in obese patients. ${ }^{[18]}$ Based on this literature, the frequency of our study is very low compared to the prevalence in Turkey. Intestinal metaplasia frequency was found as $2.64 \%$, and even though the frequency is low, it should be kept in mind that intestinal metaplasia is a premalignant lesion in terms of adenocarcinoma. ${ }^{[12]}$

Carabotti and colleagues ${ }^{[14]}$ found that postoperative complications were more frequent in obese patients with H.pylor infection. However, Almazeedi and colleagues found $7.8 \%$ helicobacter pylori infections out of 680 LSG materials in 2014, but similar to our study, they did not find a significant correlation between the presence of H.pylori and postoperative complications. ${ }^{[19]}$

Our work has a very high number of patients compared to other studies. Therefore, we believe that our results are an important reference for the histopathological findings of obese patients in our region and the frequency of H.pylori. We concluded that H.pylori infections do not have a risk of postoperative complications. However, if premalignant lesions, such as intestinal metaplasia, are suspected, we believe that preoperative endoscopic examination of the stomach should be performed.

\section{Disclosures}

Ethichs Committee Approval: The study was approved by the Local Ethics Committee.

Peer-review: Externally peer-reviewed.

Conflict of Interest: None declared.

\section{References}

1. Schirmer B, Schauer PR. The Surgical Management of Obesity. In: Schwartz's Principles of Surgery. 10th ed. New York: McGraw-Hill; 2015. p. 1099.

2. Available at: http://www.who.int/nutrition/publications/ overweight/en/. Accessed Aug 8, 2018.

3. TUiK. Türkiye Sağlık Araştırmasi, 2014. Ankara: Türkiye İstatistik Kurumu; 2014. http://www.tuik.gov.tr/HbPrint. do?id=18854. Accessed Aug 8, 2018.

4. Bozbora A. Şişmanlık Hastalığı. Genel Cerrahi. Kalaycı G, editor. İstanbul: Nobel Tıp Kitapevi; İstanbul 2002. p. 521-31.

5. Bozbora A. Morbid Obezite. Güncel Cerrahi Tedavi. 6th ed. Ergüney S, Çiçek Y, translation editor. İstanbul: Avrupa Tıp Kitapçılık; 2001. p. 105-9.

6. Steinbrook R. Surgery for severe obesity. N Engl J Med 2004;350:1075-9. [CrossRef]

7. Marceau P, Hould FS, Simard S, Lebel S, Bourque RA, Potvin $M$, et al. Biliopancreatic diversion with duodenal switch. World J Surg 1998;22:947-54. [CrossRef]

8. Himpens J, Dapri G, Cadière GB. A prospective randomized study between laparoscopic gastric banding and laparoscopic isolated sleeve gastrectomy: results after 1 and 3 years. ObesSurg 2006;16:1450-6. [CrossRef]

9. DuPree CE, Blair K, Steele SR, Martin MJ. Laparoscopic sleeve gastrectomy in patients with preexisting gastroesophageal reflux disease: a national analysis. JAMA Surg 2014;149:328-34. [CrossRef]

10. Burgerhart JS, Schotborgh CA, Schoon EJ, Smulders JF, van de Meeberg PC, Siersema PD, et al. Effect of sleeve gastrectomy on gastroesophageal reflux. ObesSurg 2014;24:143641. [CrossRef]

11. Miller GC, Reid AS, Brown IS. The pathological findings seen in laparoscopic sleeve gastrectomies for weight loss. Pathology 2016;48:228-32. [CrossRef]

12. Safaan T, Bashah M, El Ansari W, Karam M. Histopathological Changes in Laparoscopic Sleeve Gastrectomy Specimens: Prevalence, Risk Factors, and Value of Routine Histopatho- 
logic Examination. Obes Surg 2017;27:1741-9. [CrossRef]

13. Gerson LB. Impact of obesity on endoscopy. Gastrointest Endosc 2009;70:758-62. [CrossRef]

14. Carabotti M, D'Ercole C, Iossa A, Corazziari E, Silecchia G, Severi $C$. Helicobacter pylori infection in obesity and its clinical outcome after bariatric surgery. World J Gastroenterol 2014;20:647-53. [CrossRef]

15. Almazeedi S, Al-Sabah S, Al-Mulla A, Al-Murad A, Al-Mossawi A, Al-Enezi K, et al. Gastric histopathologies in patients undergoing laparoscopic sleeve gastrectomies. Obes Surg 2013;2:314-9. [CrossRef]

16. Ohanessian SE, Rogers AM, Karamchandani DM. Spec- trum of Gastric Histopathologies in Severely Obese American Patients Undergoing Sleeve Gastrectomy. Obes Surg 2016;26:595-602. [CrossRef]

17. Loewen M, Giovanni J, Barba C. Screening endoscopy before bariatric surgery: a series of 448 patients. Surg Obes Relat Dis 2008;4:709-12. [CrossRef]

18. Arslan $\mathrm{E}$, Atilgan $\mathrm{H}$, Yavaşoğlu I. The prevalence of Helicobacter pylori in obese subjects. Eur J Intern Med 2009;20:695-7.

19. Almazeedi S, Al-Sabah S, Alshammari D, Alqinai S, Al-Mulla A, Al-Murad A, et al. The impact of Helicobacter pylori on the complications of laparoscopic sleeve gastrectomy. Obes Surg 2014;24:412-5. [CrossRef] 